\title{
NUCLEAR TARGETING STUDY OF HPMA COPOLYMER-5-FLUOROURACIL CONJUGATE BASED ON THE SUBCELLULAR DISTRIBUTION IN PC-3 CELLS
}

\author{
LAN YOU ${ }^{1,2}$, SHI-YING DAI ${ }^{1}$, YUAN HUANG ${ }^{1}$, LI-MING YE $^{1}$ and CHUN-MEI FU ${ }^{1 *}$ \\ ${ }^{1}$ Key Laboratory of Drug Targeting and Drug Delivery System, Ministry of Education, \\ West China School of Pharmacy, Sichuan University, Chengdu, Sichuan 610041, China \\ ${ }^{2}$ Department of Pharmacy, West China Hospital, Sichuan University, \\ Chengdu, Sichuan 610041, China
}

\begin{abstract}
In recent decades, a large number of targeting drug delivery systems have been designed and evaluated for cancer therapy. An important part of these studies is to monitor the subcellular fate of macromolecules. Fluorescence labeling technique was the most adopted method. However, it had the disadvantages of altening the properties of drugs as well as artifactual redistribution of fluorescent markers caused by fixation. In the present study, a more accurate method, HPLC analysis preceded by subcellular fractionation was developed and validated to study the distribution of a newly synthesized tumor cell targeting drug delivery system, HPMA copolymer-5-FU conjugates (P-FU) in PC-3 cells. P-FU was proved to accumulate more in nuclei than free 5-FU, whose concentration in the culture medium was approximately $1 / 20$ that of 5-FU when attaining similar nucleus drug concentration. On the contrary, the overwhelming majority of drugs accumulated in nonnucleus when PC-3 cells were treated with free 5-FU. These results indicated that P-FU had nuclear targeting effect. The developed procedure allows an accurate subcellular fate screening for many macromolecules.
\end{abstract}

Keywords: HPLC, analysis, drug targeting, subcellular distribution, polymeric drug delivery systems

Cancer is a major public health problem in the world. Prostate cancer is the most common malignant tumor of the male urogenital system. According to the WHO global cancer epidemiology statistics statistical data (GLOBOCAN 2008), prostate cancer was the second most frequently diagnosed cancer and the sixth leading cause of cancer death in the male, accounting for $14 \%$ of the total new cancer cases and $6 \%$ of the total cancer deaths in the male in 2008 (1). In the United States, the prostate cancer, whose incidence rate accounted for $28 \%$ of all newly diagnosed cancers and the mortality accounted for $10 \%$ of the total cancer deaths in the male in 2013, was the first common cancer and the second most common cause of cancer death in men (2). In China, the incidence of prostate cancer has shown an obvious growth trend in recent years (3).

Currently, the therapeutic strategies of prostate cancer include surgical therapy, endocrine therapy, chemotherapy, radiotherapy, and combination therapy. For the treatment of advanced prostate cancer, docetaxel, mitoxantrone, estramustine, paclitaxel are the mainly used chemotherapeutic agents (4-8). However, chemo- and radiation therapies are largely ineffective against advanced prostate cancer, including non-hormone- refractory prostate carcinoma (9). So, it is of high importance to develop new therapeutic agents for prostate carcinoma which have high activity and low toxicity.

5-Fluorouracil (5-FU) has been reported to have modest antitumor activity in androgen-independent prostate cancer $(10,11)$. But strong side effects make 5-FU limited in clinical application, such as the gastrointestinal reaction, the bone suppression, and easily developed drug-resistance (12, 13). Recently, a tumor cell targeting drug delivery system, named N-(2-hydroxypropyl) methacrylamide (HPMA) copolymer-5-FU conjugate (P-FU) (Fig. 1) was synthesized and characterized and displayed superior cytotoxicity to PC-3 cells over 5-FU notably $(14,15)$. The characteristics of excellent biocompatibility, non-immunogenicity, non-toxicity

* Corresponding author: e-mail: fuchunmei@scu.edu.cn 
and modifiable structure according to different purposes, make HPMA a hydrophilic anticancer drug carrier for over 30 years. Besides, HPMA could enhance the permeability and retention of lowmolecular-weight drugs covalently conjugated to it, and then this low-molecular-weight drug, free 5-FU, released from the conjugate produced the anticancer activity (16). The fluorescence labeling internalization assay showed green fluorescence of 5-FU conjugated to HPMA was notably surrounding the nuclei (14). However, the distribution of the conjugates in PC-3 cells was unclear because the fluorescence probe was labeled on the carrier, HPMA, which has nuclear targeting effect (19) according to the reports in the literature. Then we doubt whether 5 -FU had been detached from the carrier before P-FU reaching the nucleus and whether the fluorescence signal generated around the nucleus was merely produced by the labeled HPMA. In recent decades, a large number of targeting drug delivery systems have been designed and evaluated for cancer therapy. An important part of these studies is to monitor the fate of macromolecules in cells. Fluorescence labeling technique was the most adopted

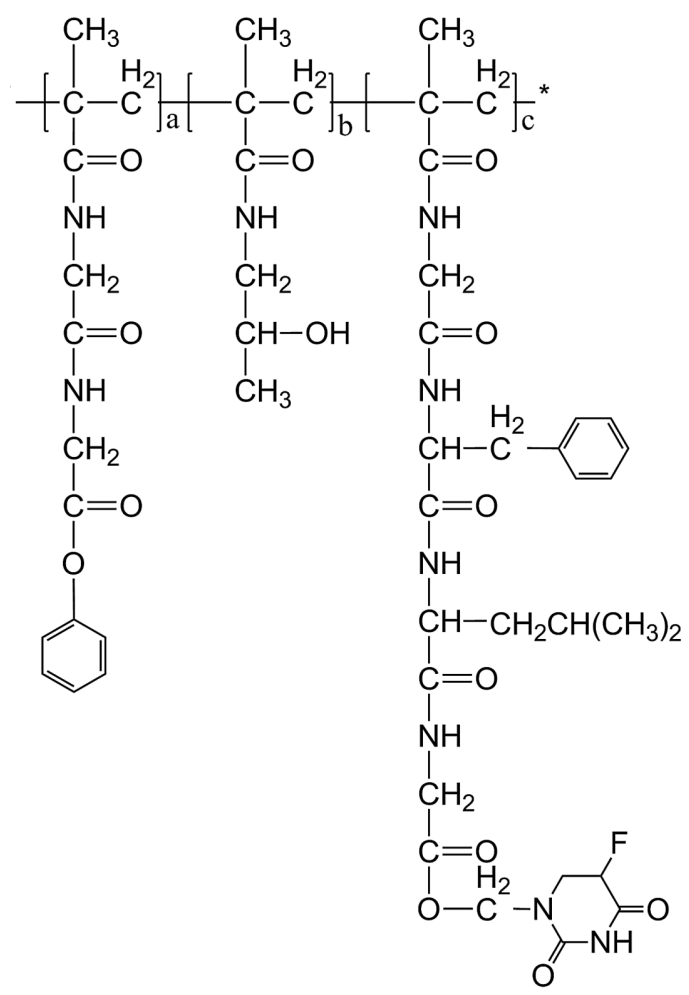

Figure 1. Chemical structure of P-FU method (16-19). However, Fluorescence labeling method also has the disadvantages of alteration of the drugs' properties and artifactual redistribution of fluorescent markers caused by fixation (19-21). Therefore, a more accurate and persuasive approach without adverse effects is essential to evaluate the nuclear targeting of P-FU.

Various methods of determination of 5-FU have been reported, and to the best of our knowledge, there is no report on the assay of 5-FU at subcellular level. Based on the internalization assay of previous literature (14) that the fluorescence was notably surrounding the nuclei, the gradient centrifugation method was adopted in this paper to divide PC-3 cells cultured with free 5-FU or P-FU into two parts, namely nuclear and nonnuclear parts. The aim of this paper is to develop an accurate method to obtain the subcellular fate of P-FU in PC3 cells, then get a further investigation of its nuclear targeting. Also, the distributions of P-FU and free 5-FU in PC-3 cells were compared to understand the higher activity against prostate cancer of P-FU than that of 5-FU.

\section{EXPERIMENTAL}

\section{Materials}

DMEM/F-12 medium was purchased from Gibco (USA). Fetal bovine serum (FBS) was provided by HyClone (USA) and penicillin (1000 $\mathrm{U} / \mathrm{mL}) /$ streptomycin $(1000 \mu \mathrm{g} / \mathrm{mL})$ was from Solarbio Science \& Technology Co., Ltd (Beijing, China). The six-well tissue culture plate was gained from Cosmo Biosciences Ltd (Beijing, China). 5-FU was from Yuancheng Gongchuang Tech Co., Ltd (Wuhan, China). Triton X-100 (100\%) was from Merck (Germany). P-FU (the drug-loading rate was $8.69 \mu \mathrm{g} / \mathrm{mg}$ ) was synthesized by Key Laboratory of Drug Targeting and Drug Delivery System, West China School of Pharmacy, Sichuan University (Chengdu, China). Trypan Blue Staining Cell Viability Assay Kit was obtained from Keygen Biotech. Co., Ltd (Nanjing, China). HPLC-grade methanol was purchased from Kermel chemical reagents company (Tianjin, China). Water was prepared by ultrapure water system (UPA, Chongqing, China). All other chemicals were of analytical grade.

\section{Cell culture and preparation of culture medium}

PC-3 prostate carcinoma cells were grown at $37^{\circ} \mathrm{C}$ in DMEM/F-12 medium with $10 \%$ fetal bovine serum (FBS) and penicillin $(100 \mathrm{U} / \mathrm{mL}) /$ streptomycin $(100 \mathrm{U} / \mathrm{mL})$ in a $5 \% \mathrm{CO}_{2} / 95 \%$ air 
incubator. P-FU (equivalent to $1.0-2.5 \mu \mathrm{g} / \mathrm{mL}$ of 5-FU) and 5-FU (10-25 $\mu \mathrm{g} / \mathrm{mL})$ were dissolved in cell culture medium and stored at room temperature.

\section{Subcellular fractionation experiment}

We developed an efficient method for separating the nucleus and nonnucleus based on the previous literature $(22,23)$. A flow chart describing the subcellular fractionation method is depicted in Figure $2.1 \mathrm{~mL}$ of $1 \%$ Triton $\mathrm{X}-100$ was added to every well to disrupt cells for $15 \mathrm{~min}$ at $4^{\circ} \mathrm{C}$. 2 wells (about $2.0 \times 10^{6}$ cells) of the disrupted cell suspensions were transferred to a $5 \mathrm{~mL}$ EP tube quantitatively. $0.5 \mathrm{~mL} 0.88 \mathrm{~mol} / \mathrm{L}$ sucrose- $1.5 \%$ citric acid solution and $0.5 \mathrm{~mL} 0.25 \mathrm{~mol} / \mathrm{L}$ sucrose- $1.5 \%$ citric acid solution were added in the disrupted cell suspensions in turn. Then the above solution was centrifuged for $10 \mathrm{~min}$ at $1000 \times g$ at $4^{\circ} \mathrm{C}$. The supernatant was nonnuclei and the sediment was nuclei. Trypan blue staining method identified that the nuclei obtained by the above method were pure (24). The nonnucleus and nucleus samples were stored at $-20^{\circ} \mathrm{C}$ until analysis.

\section{Drug subcellular distribution experiment}

PC-3 cells were seeded into six-well plates at the density of $1.0 \times 10^{5}$ cells per well and incubated for $72 \mathrm{~h}$ to a total cell number of approximately $1.0 \times 10^{6}$ per well. After incubation, the medium was removed. Then, $2 \mathrm{~mL}$ cell growth mediums containing a different concentration of P-FU or free 5-FU were added to the wells and the cells were incubated at $37^{\circ} \mathrm{C}$ for the indicated time periods. Cells in medium without drug served as controls. After incu- bating, cells were washed with PBS ( $\mathrm{pH}$ 7.4) for three times at $4^{\circ} \mathrm{C}$ and the residual fluid in the wells was totally removed before being fractionated into nonnucleus and nucleus.

\section{Sample preparation for HPLC}

After fractionating the nucleus and nonnucleus, the volume of the nonnucleus supernatant was measured and $0.5 \mathrm{~mL}$ of nonnucleus supernatant was transferred accurately to a $1 \mathrm{~mL}$-centrifugal tube with $0.5 \mathrm{~mL}$ of methanol. The mixture was sonicated for $10 \mathrm{~min}$ and next centrifuged at $1000 \times g$ for $10 \mathrm{~min}$ at $4^{\circ} \mathrm{C} .20 \mu \mathrm{L}$ of above supernatant was injected into HPLC system to determine the drug concentration in the nonnucleus sample solution.

$0.5 \mathrm{~mL}$ methanol was added into the nuclei sediment, and the mixture was eddied for $1 \mathrm{~min}$, then the solution was centrifuged at $1000 \times g$ for $10 \mathrm{~min}$ at $4^{\circ} \mathrm{C}$ and $20 \mu \mathrm{L}$ of supernatant was injected into HPLC system to determine the drug concentration in nucleus sample. Operation process is shown in Figure 3.

\section{HPLC chromatography}

HPLC determinations were performed with a Shimadzu model 20A liquid chromatographic system (Tokyo, Japan), consisting of an LC-10AB pump and a DAD detector ( SPD-M20A ). The analytical column was an Alltima ${ }^{\mathrm{TM}} \mathrm{C}_{18}$ column $(5 \mu \mathrm{m}$, $4.6 \times 250 \mathrm{~mm})$. The elution with a mobile phase of $0.1 \%$ tetrabutylammonium hydroxide $(\mathrm{pH} \mathrm{7.0,}$ adjusted by phosphate)-methanol (95:5, v/v) was used at a flow rate of $1.0 \mathrm{~mL} / \mathrm{min}$ for the separation of an analyte. The analyte is monitored at the UV wavelength of $265 \mathrm{~nm}$.

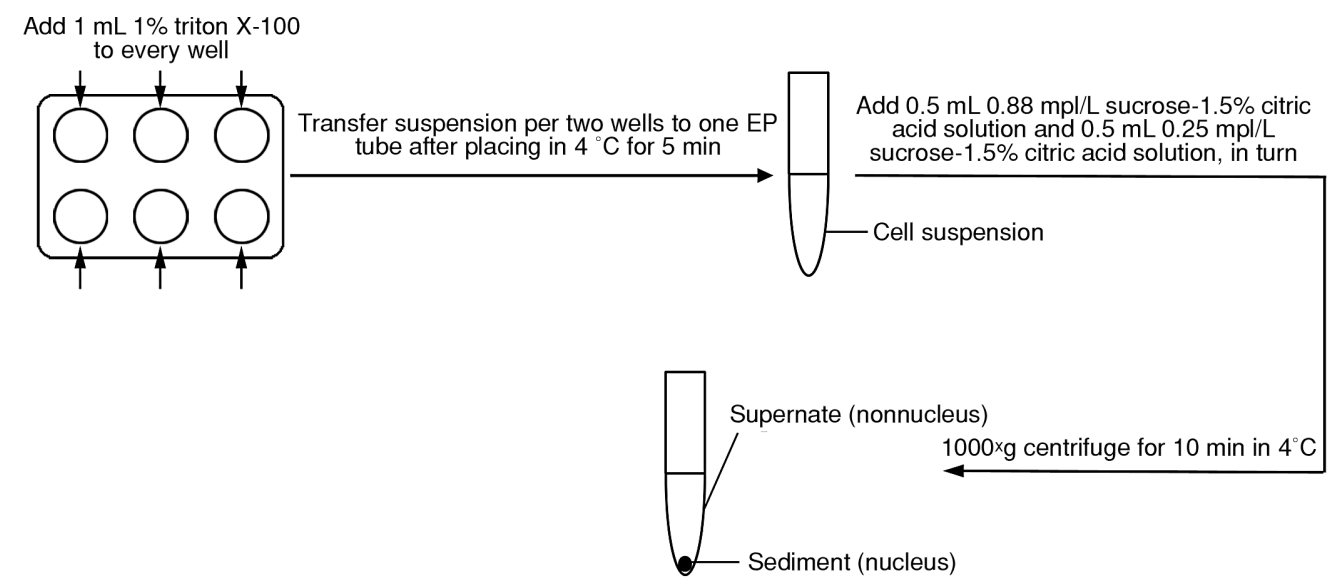

Figure 2. The flow chart of cell sample processing 


\section{HPLC method validation \\ Selectivity}

HPLC peak of 5-FU was identified on the basis of its retention time and UV spectra obtained by DAD detector. Nonnucleus and nucleus samples from drug-free PC-3 cells were tested for the presence of endogenous compounds co-eluting with $5-\mathrm{FU}$.

\section{Calibration curves, limits of detection and quan- tification}

A standard stock solution of 5-FU was prepared in methanol, and diluted freshly with methanol in various concentrations as working standard solutions. An aliquot of $20 \mu \mathrm{L}$ working standard solution was injected into the HPLC for analysis. Nucleus and nonnucleus standard samples for calibration and quality control (QC) were prepared daily by spiking blank nuclei and $0.5 \mathrm{~mL}$ blank nonnuclei with 0.5 $\mathrm{mL}$ 5-FU standard solution to achieve concentrations in the range of $0.1015-4.060 \mu \mathrm{g} / \mathrm{mL}$. Then they were processed as described in "sample preparation for HPLC". The calibration curves were established in triplicate, with their regression equations calculated. The stock solution was diluted to a series of concentrations and then spiked into blank nuclei and blank nonnuclei for determining the validation work on limits of detection (LOD) and quantification (LOQ) at a signal-to-noise $(\mathrm{S} / \mathrm{N})$ ratio of 3 and 10 , respectively.

\section{Precision and recovery}

The intra-day precision of the assay was estimated by analyzing five replicates of QC samples at three different concentrations $(0.1015,0.2030$ and $1.015 \mu \mathrm{g} / \mathrm{mL}$ in nuclei, $0.1015,1.015$ and 2.030 $\mu \mathrm{g} / \mathrm{mL}$ in nonnuclei). The inter-day precision was determined from the results of assays of QC samples of five consecutive days. Recovery was determined by comparing peak areas of spiked samples with those obtained from direct injection of the compounds dissolved in methanol.

\section{Stability}

The ambient stability, freezer stability and freeze-thaw stability of 5-FU in nuclei and nonnuclei were assessed using the QC samples of three different concentrations $(0.1015,0.2030$ and 1.015 $\mu \mathrm{g} / \mathrm{mL}$ in nuclei, $0.1015,0.5075$ and $1.015 \mu \mathrm{g} / \mathrm{mL}$ in nonnuclei). The ambient stability was assessed by leaving the QC samples at room temperature for $8 \mathrm{~h}$. The freezer stability was assessed by leaving the QC samples at $-20^{\circ} \mathrm{C}$ for 15 days. The freeze-thaw stability was assessed over three cycles thawed at room temperature and refrozen at $-20^{\circ} \mathrm{C}$.

\section{RESULTS AND DISCUSSION}

In this paper, the concentration of prototype drug 5-FU was determined to reflect the content of P-FU. So in order to determine the total amount of

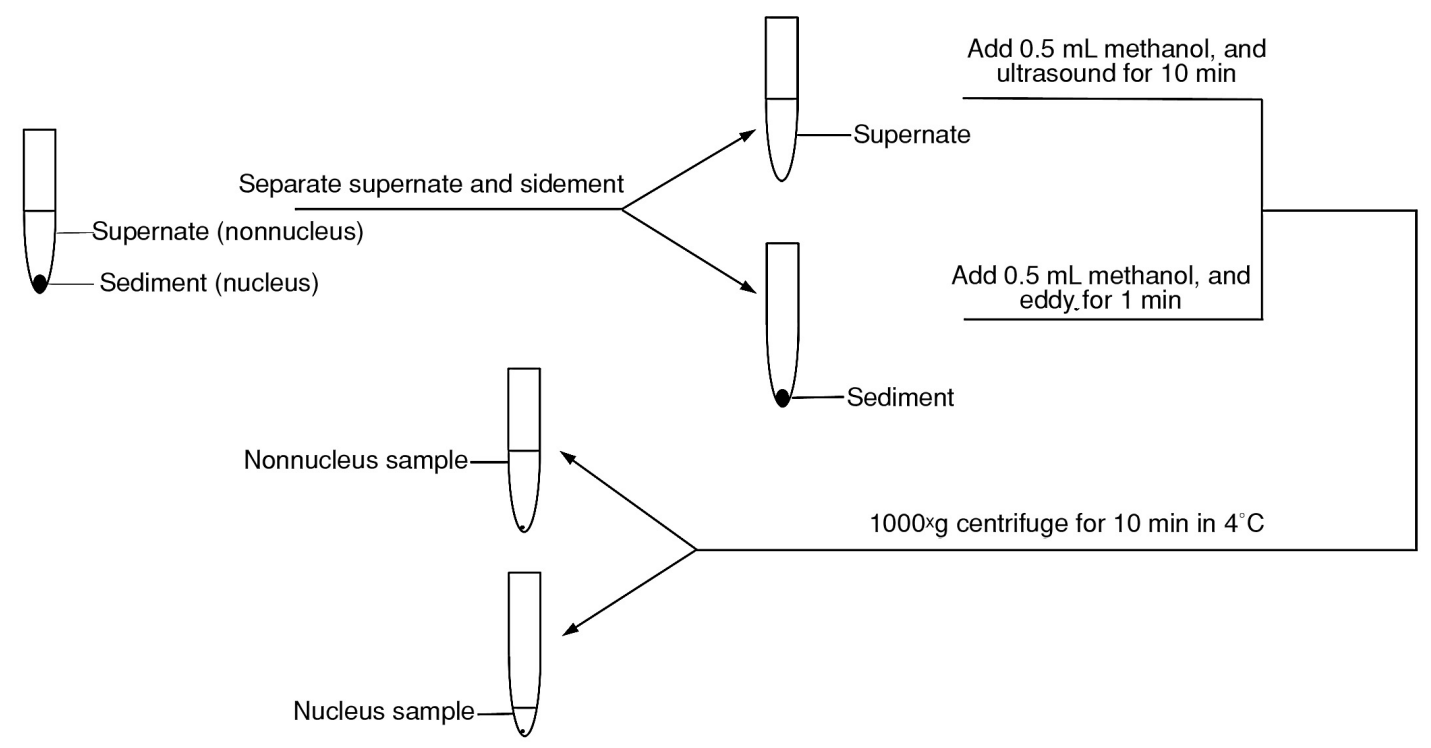

Figure 3. The flow chart of the sample preparation for HPLC 

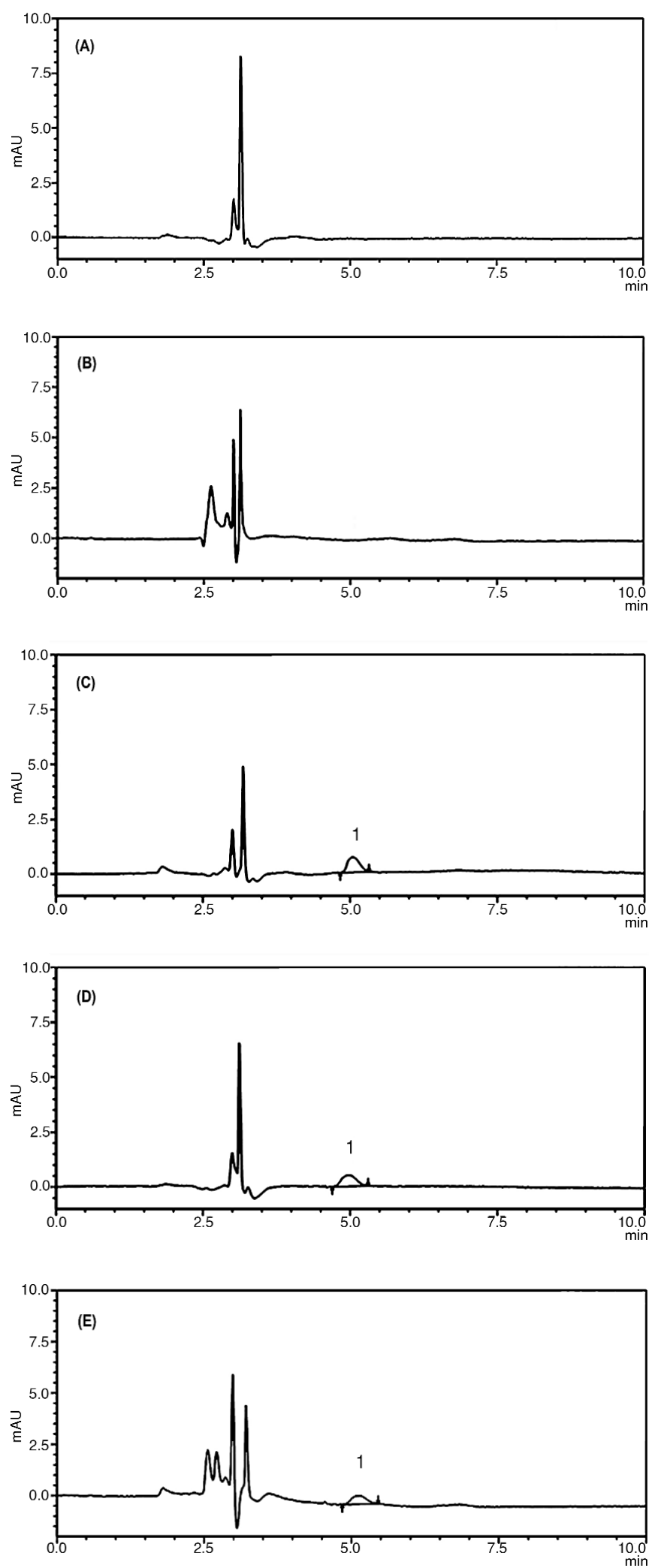

Figure 4. Representative HPLC chromatograms of Selectivity. Representative HPLC chromatograms of (A) blank nucleus; (B) blank nonnucleus; (C) nucleus sample after incubated with $1.0 \mu \mathrm{g} / \mathrm{mL} \mathrm{P-FU} \mathrm{for} 24 \mathrm{~h}$; (D) nucleus sample after incubated with $20 \mu \mathrm{g} / \mathrm{mL} \mathrm{5-FU} \mathrm{for}$ $24 \mathrm{~h}$; (E) nonnucleus sample after incubated with $10 \mu \mathrm{g} / \mathrm{mL} 5-\mathrm{FU}$ for $24 \mathrm{~h}$. Peak 1 is 5-FU. 
5-FU, including conjugated and released drug, both nuclei and nonnuclei samples from cells treated with P-FU were hydrolyzed by sodium hydroxide $(\mathrm{NaOH})$ solution $(0.1 \mathrm{M})(14)$. The results showed that the amount of 5-FU determined after hydrolyzing was coincident with that determined directly. It's indicated that 5-FU and HPMA were basically separated after nuclear and nonnuclear samples being treated with a series of destructive operations such as vortex, ultrasound and high-speed centrifugation.

Protein precipitation was adopted to prepare nonnuclei sample to reduce the interference of endogenous components. Methanol and acetonitrile were used as protein precipitation reagents and the sample-solvent ratios of $1: 1,1: 2$ and $1: 3(\mathrm{v} / \mathrm{v})$ were evaluated. From the experiment, equal amounts of nonnucleus sample and methanol showed the highest extraction recovery and detection sensitivity.

According to the pretreatment method of nonnucleus sample, methanol was used to extract 5-FU in nucleus. In this study, ultrasonic extraction and vortex were used to release 5-FU from nucleus. Viewed under optical microscope, the nuclei were ruptured completely after eddying for $1 \mathrm{~min}$ and higher extraction recovery was achieved.

As for HPLC method validation, no interfering peaks were observed in any of the nucleus and nonnucleus samples used in our studies. Representative chromatograms are shown in Figure 4, The peaks of 5-FU were demonstrated to be pure and the peak purity indexes were all over 0.999 .

The linearity of the method was evaluated by analyzing six calibration standards over the concentration range of $0.1015-4.060 \mu \mathrm{g} / \mathrm{mL}$ for 5 -FU in methanol, blank nuclei, and blank nonnuclei. The regression equations of 5-FU in methanol, blank nuclei and blank nonnuclei were $\mathrm{y}=56399 \mathrm{x}^{-2} 2128$ $\left(\mathrm{R}^{2}=0.9996\right), \mathrm{y}=52316 \mathrm{x}^{-} 3648.3\left(\mathrm{R}^{2}=0.9959\right)$ and $y=63180 x^{-} 5591.3\left(R^{2}=0.9968\right)$, respectively. The LOQs of 5-FU were $77.1 \mathrm{ng} / \mathrm{mL}$ in nuclei and 35.5 $\mathrm{ng} / \mathrm{mL}$ in nonnuclei, and the LODs were $22.3 \mathrm{ng} / \mathrm{mL}$ in nuclei and $10.1 \mathrm{ng} / \mathrm{mL}$ in nonnuclei, respectively. Intra-day and inter-day precision results of the method assessed by analyzing quality control samples were obtained, for concentrations of calibration standards ranging from 0.1015 to $4.060 \mu \mathrm{g} / \mathrm{mL}$, the RSD values did not exceed $15 \%$ (Table 1). The recovery of 5-FU from nuclei averaged $96.1 \%$ (RSD $=2.8 \%, \mathrm{n}=15)$ and $97.2 \%(\mathrm{RSD}=4.2 \%, \mathrm{n}=15)$ from nonnuclei (Table 1).

Stability investigation demonstrated that the concentrations of 5-FU in processed samples had no significant difference within $8 \mathrm{~h}$ at $25^{\circ} \mathrm{C}$. The mean percentage recovery $(100 \% \times$ (measured concentration/added concentration)) of spiked samples stored at $-20^{\circ} \mathrm{C}$ for 15 days ranged from $93.1 \%$ to $95.7 \%$ and the RSDs were less than $5.8 \%$. The mean percentage recovery of samples subjected to three freeze-thaw cycles ranged from $95.5 \%$ to $100.1 \%$ and the RSDs were less than $4.9 \%$. These indicated that 5-FU added to nuclei and nonnuclei was stable at different conditions.

On one hand, the stronger activity of many drugs depending on their subcellular location and increasing fraction of target reaching and interacting amount would decrease the dose requirements (19), on the other hand, the conjugates releasing the combined drug successfully after the distribution in tumor tissues is the prerequisite of polymer drug delivery system developing antitumor effect (25). Besides, 5-FU exerts anticancer effects through inhibition of thymidylate synthase (TS) and incor-

Table 1. Recovery, intra- and inter-day precision of the HPLC analysis $(n=5)$.

\begin{tabular}{|c|c|c|c|c|c|c|c|}
\hline \multirow{2}{*}{$\begin{array}{c}\text { Nominal } \\
\begin{array}{c}\text { concentration } \\
(\mu \mathrm{g} / \mathrm{mL})\end{array}\end{array}$} & $\begin{array}{c}\text { Recovery } \\
(\mu \mathrm{g} / \mathrm{mL})\end{array}$ & $\begin{array}{c}\text { Recovery } \\
(\%)\end{array}$ & $\begin{array}{c}\text { Determined } \\
(\mu \mathrm{g} / \mathrm{mL})\end{array}$ & $\begin{array}{c}\text { Precision } \\
(\%)\end{array}$ & \multicolumn{2}{c|}{$\begin{array}{c}\text { Determined } \\
(\mu \mathrm{g} / \mathrm{mL})\end{array}$} & $\begin{array}{c}\text { Precision } \\
(\%)\end{array}$ \\
\cline { 2 - 7 } & \multicolumn{7}{|c|}{ Nuclear } \\
\hline 0.1015 & 0.0966 & 95.2 & 0.0971 & 4.1 & 0.0948 & 3.4 \\
\hline 0.2030 & 0.1969 & 97.0 & 0.2037 & 3.3 & 0.2050 & 7.9 \\
\hline 1.0150 & 0.9740 & 96.0 & 0.9730 & 3.5 & 0.9900 & 2.6 \\
\hline 0.1015 & 0.0992 & 97.7 & 0.0992 & 5.2 & 0.0952 & 7.9 \\
\hline 1.0150 & 1.0000 & 98.5 & 0.9930 & 4.4 & 1.0110 & 5.8 \\
\hline 2.0300 & 1.9380 & 95.5 & 2.0160 & 4.7 & 1.9770 & 6.6 \\
\hline
\end{tabular}


Table 2. Determined 5-FU in nuclear and nonnuclear parts of PC-3 cells treated with P-FU or free 5-FU for $24 \mathrm{~h}(\mathrm{n}=3)$.

\begin{tabular}{|c|c|c|c|c|}
\hline \multirow{2}{*}{$\begin{array}{c}\text { Concentration of P-FU } \\
\text { (5-FU, equiv.) or free } 5 \text {-FU } \\
\text { in the culture medium } \\
(\mu \mathrm{g} / \mathrm{mL})\end{array}$} & \multicolumn{2}{|c|}{ Determined 5-FU in nuclear part } & \multicolumn{2}{|c|}{ Determined 5-FU in nonnuclear part } \\
\hline & Amount $(\mu \mathrm{g})^{*}$ & Percentage $(\%)^{\#}$ & Amount $(\mu \mathrm{g})^{*}$ & Percentage $(\%)^{\#}$ \\
\hline \multicolumn{5}{|c|}{ P-FU } \\
\hline 0.8 & - & - & - & - \\
\hline 1.0 & $0.0703 \pm 0.0042$ & 3.52 & - & - \\
\hline 1.1 & $0.0747 \pm 0.0031$ & 3.40 & - & - \\
\hline 1.5 & $0.0956 \pm 0.0046$ & 3.19 & - & - \\
\hline 2.0 & $0.1027 \pm 0.0051$ & 2.57 & - & - \\
\hline 2.5 & $0.1248 \pm 0.0045$ & 2.50 & - & - \\
\hline \multicolumn{5}{|c|}{ 5-FU } \\
\hline 10 & - & - & $0.3276 \pm 0.0092$ & 1.64 \\
\hline 20 & $0.0546 \pm 0.0020$ & 0.14 & $2.9664 \pm 0.0890$ & 7.42 \\
\hline 25 & $0.1704 \pm 0.0043$ & 0.34 & $4.7199 \pm 0.0850$ & 9.44 \\
\hline
\end{tabular}

* Data are expressed as the amount of determined 5-FU in one well of PC-3 cells treated with P-FU or free 5-FU and mean \pm SD; ${ }^{*}$ data are expressed as a percentage (Determined 5-FU amount/ P-FU or free 5-FU amount administrated in the culture medium $\times 100 \%$ ); "-" undetectable

poration of the metabolites into RNA and DNA which mainly exist in nucleus (26). It is suggested that the nuclear targeting property is an essential condition for 5-FU to play the role of anti-cancer. Consequently, it's significant and reliable to measure the amount of 5-FU to represent the subcellular fate of P-FU in PC-3 cells, and thus reflecting that the anti-cancer activity of $\mathrm{P}$-Fu was in a more efficient way than that of 5-FU.

The developed method, HPLC analysis proceeded by subcellular fractionation was applied to study the distribution of P-FU and free 5-FU in PC3 cells to understand their different pharmacological activities. The concentrations of drugs in the culture media were set according to the results of apoptosis assay (14) and our preliminary experiment. For further experiments, culture media containing 1.0, 1.1, $1.5,2.0,2.5 \mu \mathrm{g} / \mathrm{mL}$ of P-FU (5-FU, equiv.) and 10, $20,25 \mu \mathrm{g} / \mathrm{mL}$ of free $5-\mathrm{FU}$ were used. If a higher concentration of P-FU was used, the error would increase because of cell apoptosis.

In this study, cells were incubated with P-FU for 2, 4, 12 and $24 \mathrm{~h}$. The results showed that the concentration of P-FU in nucleus samples was lower than LOD when the cells were incubated with 2.5 $\mu \mathrm{g} / \mathrm{mL}$ of P-FU (5-FU, equiv.) for 2 or $4 \mathrm{~h}$, and was approximately equal to the LOQ when the incubation time was $12 \mathrm{~h}$. So $24 \mathrm{~h}$ was chosen as the incubation time. The determined 5-FU amount, as well as the percentage (determined 5-FU amount/ P-FU or free 5-FU amount administrated in the culture medium $\times 100 \%$ ) in nonnuclei and nuclei after PC3 cells being incubated with P-FU or free 5-FU for 24 h, were shown in Table 2 and Figure 5.

In the range of P-FU (5-FU, equiv.) administration concentration in $1.0-2.5 \mu \mathrm{g} / \mathrm{mL}$, the amount of 5-FU in nonnuclear part was undetectable, while in nuclear part it was increased along with the drug concentration administrated in the culture medium, which validated the result that the uptake amount of P-FU for $24 \mathrm{~h}$ incubation was a concentrationdependent process (Table 2, Fig. 5) (14). Besides, the relationship was almost linear (Fig. 5), which has coincided with the result that HPMA copolymer showed a steadily increased amount of internalization in Hep G2 cells after being incubated with various concentrations of the polymers for 24 hours (27). On the contrary, the overwhelming majority of 5-FU was accumulated in nonnuclei (over $96.5 \%$ uptake of 5-FU was in nonnuclear part) when PC-3 cells were treated with free 5-FU. Comparing with free 5-FU, the concentration of P-FU (5-FU equiv) in the culture medium was approximately $1 / 20$ of that of free 5-FU when the nucleus drug amount achieved similar level, which coincided with the experimental results that the $\mathrm{IC}_{50}$ of P-FU to PC-3 cells ( $54.12 \pm$ $2.43 \mu \mathrm{g} / \mathrm{mL} 5$-FU equiv) was about $1 / 20$ of that of 5-FU $(814.1 \pm 151.1 \mu \mathrm{g} / \mathrm{mL})(14)$. All the data indicated that P-FU does possess excellent nuclear targeting effect, which could contribute to reducing the noxious and unintended adverse drug reactions that occur commonly to some extent. 

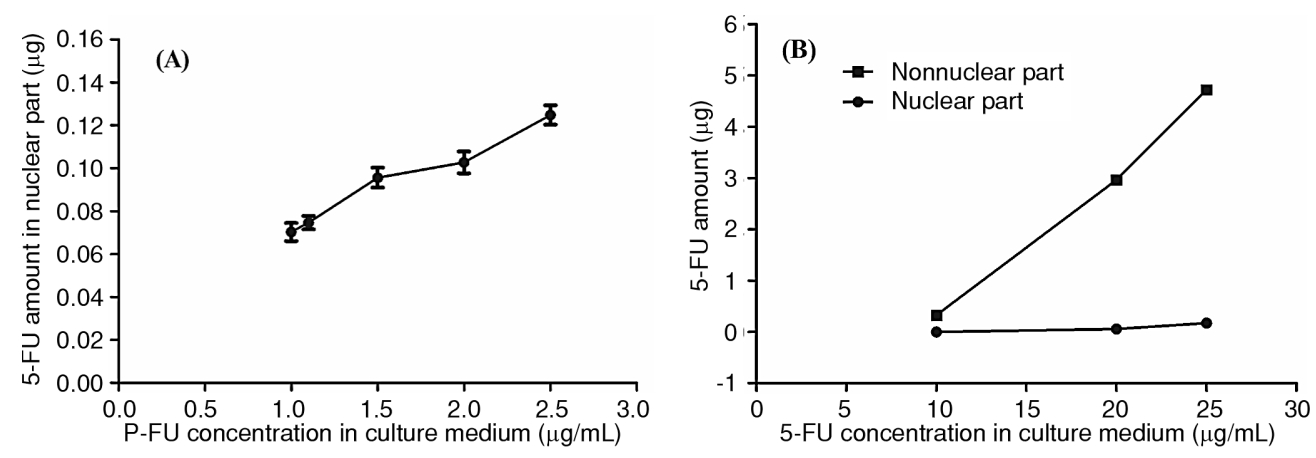

Figure 5. Quantitative measurement of 5-FU in nuclear and nonnuclear parts of PC-3 cells. PC-3 cells were exposed to medium containing (A) 1.0, 1.1, 1.5, 2.0, $2.5 \mu \mathrm{g} / \mathrm{mL}$ P-FU (5-FU, equiv.); (B) 10, 20, $25 \mu \mathrm{g} / \mathrm{mL}$ free 5-FU for $24 \mathrm{~h}$. The results are expressed as the amount in one well

The overwhelming majority of 5-FU accumulated in nonnuclei when PC-3 cells were treated with free 5-FU (Table 2), which probably could be explained by the drug resistance of 5-FU: the diffusion way of entering cells made 5-FU available for the special transmembrane proteins and be pumped out from the cellular cytoplasm, and this activity conducted by the transporter proteins responsible for pump resistance like P-glycoproteins (PGP) and multidrug resistance-associated proteins (MRP) leaded to the reduction of intracellular drug concentration $(28,29)$. In contrast, HPMA copolymerbound drugs' intracellular trafficking was along the endocytic pathway (30). Reviewing the synthesis of P-FU, 5-FU was attached to the polymer backbone via the lysosomally degradable Gly-Phe-Leu-Gly (GFLG) peptide allowing intracellular release by lysosomal proteases (31). Consequently, P-FU may enter cells by endocytosis, then the endosome, containing HPMA copolymer-bound drugs, were transported to lysosomes accumulating in perinuclear area, and 5-FU was released and entered the nucleus after lysosomal enzymes digesting the spacer (14, 32). Due to these two different cellular uptake modes, always two kinds of different concentration gradients were produced, that the concentration gradient of free drugs was in direction of diffusion from the plasma membrane to perinuclear region, while the polymer-bound drugs were in the opposite direction (30). As the result showed that obvious concentration gradients of 5-FU in nuclear and nonnuclear parts after PC-3 cells being treated with P-FU or free 5-FU were obtained (Table 2).

\section{CONCLUSION}

The current study highlighted that a more accurate method, HPLC analysis preceded by sub- cellular fractionation was developed to study the distribution of a macromolecular anti-tumor reagent, HPMA copolymer-5-FU conjugate, in PC3 cells. And the results provided P-FU the sufficient basis of a more efficient nuclear targeting. Since many drugs today are being designed to work at specific sites within cells and the subcellular distribution of many drugs remains unclear, so the knowledge of the internalization and subcellular fate of macromolecules is paramount for designing a viable therapy $(19,33)$. Fluorescence labeling technique, which is the most adopted method, is sensitive and intuitive to monitor the internalization and subcellular fate of macromolecules. But it has the disadvantages of alteration of the drugs' properties and artifactual redistribution of fluorescent markers caused by fixation. Furthermore, fluorescence labeling technique is a semi-quantitative technique, and fluorescent markers are usually linked with the carriers, not the drugs, so the achieved results by this method would not be very accurate.

Besides, as there came out a series of dual drug-loaded conjugates possessed excellent synergistic anticancer activity $(34,35)$, the more direct results could be obtained separately through the method established in this paper which could meet the requirements for respective and accurate subcellular distribution study of the drugs. However, the antineoplastic effects of 5-FU are caused by the active metabolites, so adopting more sensitive analytical methods to study the distribution of active metabolites in organelles may be more convincing. Although there are much to improve, this paper presents a reliable and feasible method for monitoring the subcellular distribution of targeting drug delivery systems. 


\section{Acknowledgments}

This study was supported by the National Natural Science Foundation of China (Grant No. 81473167).

\section{Conflict of interest}

The authors declare no conflict of interest.

\section{REFERENCES}

1. Jemal A., Bray F., Center M.M., Ferlay J., Ward E., Forman D.: CA. Cancer J. Clin. 61, 69 (2011).

2. Siegel R., Naishadham D., Jemal A.: CA. Cancer J. Clin. 63, 11 (2013).

3. Han S.J., Zhang S.W., Chen W.Q., Li C.L.: Chin. Clin. Oncol. 18, 330 (2013).

4. Chowdhury S., Burbridge S., Harper P.G.: Int. J. Clin. Pract. 61, 2064 (2007).

5. Tannock I.F., de Wit R., Berry W.R., Horti J., Pluzanska A. et al.: N. Engl. J. Med. 351, 1502 (2004).

6. Garzotto M., Higano C.S., O'Brien C., Rademacher B.L., Janeba N. et al.: Cancer 116, 1699 (2010).

7. Di Lorenzo G., Autorino R., Perdona S., De Laurentiis M., D'Armiento M. et al.: Eur. Urol. 52, 1020 (2007).

8. Friedman J., Dunn R.L., Wood D., Vaishampayan U., Wu A. et al.: J. Urol. 179, 911 (2008).

9. Gilligan T., Kantoff P.W.: Urology 60, 94 (2002).

10. Daliani D.D., Eisenberg P.D., Weems J., Lord R., Fueger R., Logothetis C.J.: J. Urol. 153, 1587 (1995).

11. Chao D., Von Schlippe M., Harland S.J.: Eur. J. Cancer 33, 1230 (1997).

12. Nichifor M., Schacht E.H., Seymour L.W.: J. Control Release 48, 165 (1997).

13. Mader R.M., Muller M., Steger G.G.: Gen. Pharmacol. 31, 661 (1998).

14. Yang Y., Zhou Z., He S., Fan T., Jin Y. et al.: Biomaterials 33, 2260 (2012).

15. Yuan F., Zhang Z.R., Yang Y. X., Huang Y.: Yao xue xue bao 43, 1152 (2008).
16. Rihova B., Kopeckova P., Strohalm J., Rossmann P., Vetvicka V., Kopecek J.: Clin. Immunol. Immunopathol. 46, 100 (1988).

17. Tijerina M., Kopeckova P., Kopecek J.: Pharm. Res. 20, 728 (2003).

18. Barz M., Arminan A., Canal F., Wolf F., Koynov K. et al.: J. Control Release 164, 63 (2012).

19. Jensen K.D., Nori A., Tijerina M., Kopeckova P., Kopecek J.: J. Control Release 87, 89 (2003).

20. Sui M., Liu W., Shen Y.: J. Control Release 155, 227 (2011).

21. Lundberg M., Johansson M.: Biochem. Biophys. Res. Commun 291, 367 (2002).

22. Bonifacino J.S., Dasso M., Harford J.B., Lippincott-Schwartz J., Yamada K.M.: Science Press 2007.

23. Cui W., Hu R., Chang Y., Jiang Q.: J. Heal. Toxicol. 4, 189 (1990).

24. Feng W.S., Ruan C.J., Feng Z., Qiu Z.N., Gu P., Zhang H.B.: J. Clin. Rehab. Tissue. Eng. Res. 12, 5788 (2008).

25. Ulbrich K., Subr V.: Adv. Drug. Deliv. Rev. 56, 1023 (2004).

26. Longley D.B., Harkin D.P., Johnston P.G.: Nat. Rev. Cancer 3, 330 (2003).

27. Jensen K.D., Kopeckova P., Bridge J.H., Kopecek J.: AAPS. PharmSci. 3, (2001).

28. Szakacs G., Jakab K., Antal F., Sarkadi B.: Pathol. Oncol. Res. 4, 251 (1998).

29. Van Veen H.W., Konings W.N.: Biochim. Biophys. Acta. 1365, 31 (1998).

30. Omelyanenko V., Kopeckova P., Gentry C., Kopecek J.: J. Control. Release 53, 25 (1998).

31. Xiang Q., Yang Y., Zhou Z., Zhou D., Jin Y. et al.: Eur. J. Pharm. Biopharm. 80, 379 (2012).

32. Minko T.: Adv. Drug Deliv. Rev. 62, 192 (2010)

33. Ahmed M.F., Youns M., Belal A.: Acta Pol. 73, 115 (2016).

34. Yang Q., Yang Y., Li L., Sun W., Zhu X., Huang Y.: ACS. Appl. Mater. Interfaces. 7, 6661 (2015).

35. Vicent M.J., Greco F., Nicholson R.I., Paul A., Griffiths P.C., Duncan R.: Angew. Chem. Int. Ed. Engl. 44, 4061 (2005).

Received: 13.09. 2017 